\title{
2 \\ Patterns of Transnational Trade Union Cooperation in Europe
}

\begin{abstract}
This chapter offers an overview of patterns of transnational trade union cooperation-based on empirical data. It begins by providing a brief depiction of the multilevel structures of such cooperation, followed by a presentation of the general views among unions regarding the importance and the potential benefits of cooperating at different levels. A second section entails a more detailed investigation of the importance attributed to various topics to collaborate on. This part also includes an examination of the preferences among unions in different sectors and industrial relations regimes/regions regarding forms of cooperation. The remainder of the chapter section scrutinizes what unions consider to be the most important obstacles to and facilitators for cross-border cooperation.
\end{abstract}

Keywords Transnational trade union cooperation - Europe - Topics • Obstacles · Facilitators 


\section{Introduction}

The existence of meta-organizations like the ETUC and the ETUFs, treated in Chapter 1, obviously implies a great deal of cooperation between trade unions in Europe. Even though labour organizations are generally based on national affiliation, we see a long history of internationalism in the trade union movement through both supranational organizations and bilateral contacts and actions (Gumbrell-McCormick and Hyman 2013: 158-161; cf. Gajewska 2009; Seeliger 2019: 14-22). An illustration of how transnational cooperation is highlighted as a joint effort at European level comes from the ETUC action program 20192023:

In recent years we-the ETUC and its affiliates-have significantly strengthened our internal cooperation and coordination. We have agreed on common policies by overcoming the existing differences between east and west, north and south. We have created efficient networks and practices within the ETUC to involve and mobilise our affiliates. We have significantly increased our influence on institutions, at both EU and national level. (ETUC 2019: 8)

Naturally, the level of international activities among the national members of the ETUC and the ETUFs or between trade unions below these peak-level confederations varies across countries and sectors as well as with organizational resources. Some large organizations are active not only in exchange with and support to sister organizations in other countries but are also central drivers and actors on different topics. However, even unions with very small resources and less international activity may actually have strong latent networks of contacts, which can be used when needed — as demonstrated by this quotation from a Baltic interviewee:

[With some] countries, our cooperation is only a few e-mails [from] time to time, when there is a need... We have more or less at least one person in every country [to whom] we can write or phone to ask some questions. But, the reality is that, like every trade union, we are very busy at the national level, so there are not a lot of international questions we are involved in. 
In our two surveys to trade unions, a majority confirmed the general importance of pursuing transnational union cooperation. In survey 1 , almost all responding unions (94\%) agreed with a statement that crossnational union cooperation will, in the long run, improve conditions for European workers (Larsson 2014). In survey 2, the financial and economic crisis starting in 2008 was said to have had negative effects on transnational cooperation. Over 60\% stated that the crisis had made the outlooks of unions more protectionist, thereby substantiating discussions pointing to a 'renationalization' of attitudes during the last decade or so (Lehndorff et al. 2017: 30). Despite this, 70\% of the responding unions reported that they had actually increased cooperation with other unions in Europe because of the crisis. In addition, over $40 \%$ of the respondents declared that their organization desired even more transnational cooperation in the future (Bengtsson and Vulkan 2018).

In order to unpack such overall ambitions to cooperate for the purpose of improving the conditions for European workers, we need to examine what cooperation between unions really is and what conditions that hinder or facilitate it. In the next section, we begin by introducing a theoretical typology of different collaborative structures and then look at the existing levels of collaboration and how important these are according to the trade unions themselves. Thereafter we focus on the general topics that unions cooperate on and which forms the organizations prefer. The final part of the chapter elaborates the issue of what factors make up important obstacles and facilitators for cooperation.

\section{Multilevel Structures of Cooperation}

Theoretically, it is possible to distinguish at least four kinds of cooperative structures signifying different degrees of institutionalization (cf. Müller and Platzer 2017: 294; Müller et al. 2010). (1) The least institutionalized structure consists of bi- or multilateral communication networks. Through such networks, national unions can use information from other unions in developing their national or European-level strategies, while still acting independently of others. (2) At the next level, national organizations work jointly to identify common interests and 
form loose coordination networks. This enables them to synchronize their individual actions across countries or at supranational level, for example by matching national collective bargaining or positions to be taken in the ESD, while even then acting autonomously. (3) A still stronger degree of institutionalization is the development of joint activities on a case-bycase basis in cooperation networks. Examples of such cooperation can be activities like seminars, training or demonstrations, comprising unions from more than one country. (4) The most institutionalized cooperative structure exists when trade unions together form supranational and staffed meta-organizations, that is, with other organizations as members and with a decision-making assembly or a mandate to act on behalf of its affiliates or concert their actions on a more long-term basis (Ahrne and Brunsson 2008). The ETUC and the ETUFs are the main examples at European level.

All of these forms of cooperation exist in Europe and they are only separable analytically. In practice, they are intertwined, since 'joint efforts to build formalized supranational structures for coordination contribute to creating corresponding informal structures (e.g., trust) as a by-product' (Traxler and Mermet 2003: 237). As a consequence, bi- or multilateral communication networks and concerted collaboration through the ETUC and the ETUFs mutually reinforce each other. In that way, top-down and bottom-up processes of cooperation and coordination blend in a multilevel structure (Marginson and Sisson 2004; Keune and Marginson 2013). According to this line of argument, the more concertation there is of action, the stronger the networks of bilateral exchange and informal coordination from below tend to become.

Transnational trade union cooperation simultaneously takes place at various organizational levels and in various regional contexts. From our interviews, we see that unions are active at different levels, from the local to the global. Whereas in small organizations the same individuals may have to be implicated in almost everything, in larger unions there can be an internal division of labour. However, in the practical work around specific topics, the different levels tend to be interwoven also in larger organizations, as shown in this quote from a Swedish union representative: 
For us, it is not like 'now we work on European issues' or 'now we work on global issues'... There are several arenas: there is a local, a regional, a national, and there is a European and a global arena. We should be present everywhere-they are all entangled.

By creating a generalized map of a single Swedish trade union's relations to other organizations-both directly to other counterparts and to metaorganizations - it is possible to illustrate the complexity of the multilevel structure of cooperation (Fig. 2.1). The actually existing structures of course vary between countries, sectors and individual unions; the rationale for departing from a Swedish union is that we want to include regional cross-country organizations in the map and those are well developed in the Nordic region.

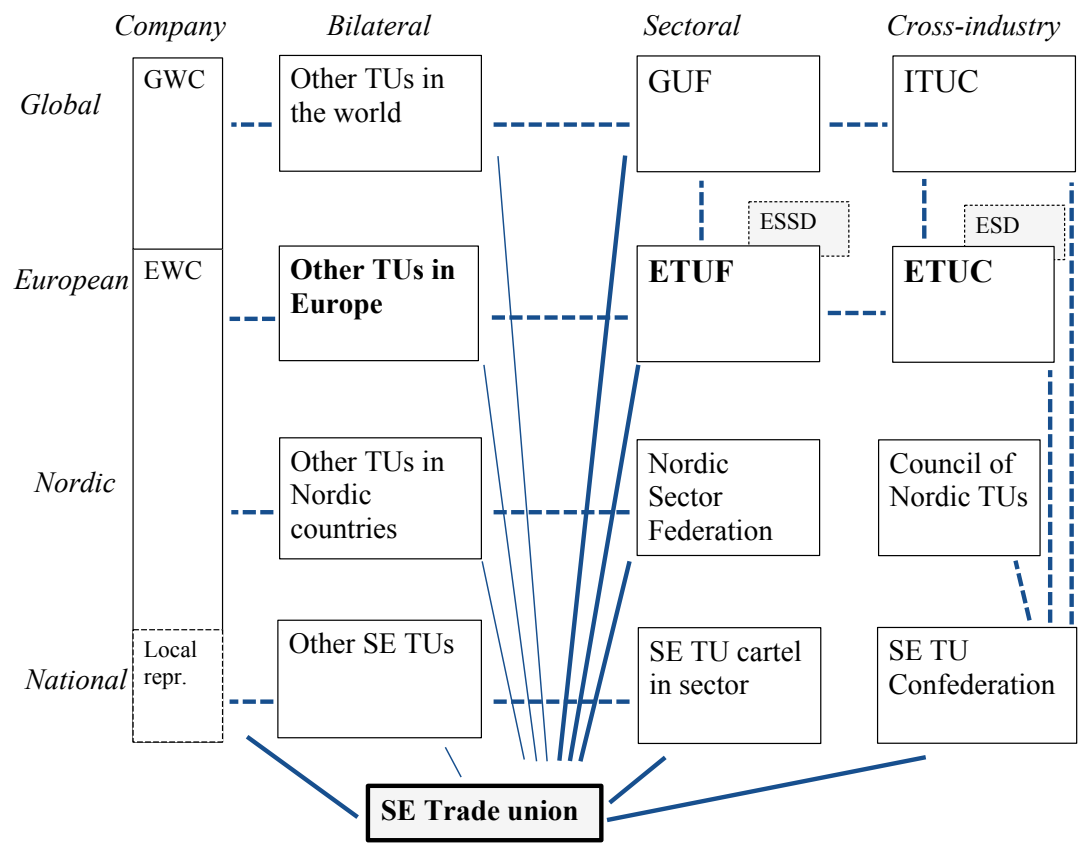

Fig. 2.1 Generalized map of a trade union cooperation structure.

Note GUF = Global Union Federation; GWC = Global Works Council; ITUC = International Trade Union Confederation; SE = Sweden; TU = trade union 
Figure 2.1 should be read as follows: The individual union that is the starting point for the structure is placed at the bottom. Thin lines indicate direct bilateral cooperation with other unions within or outside its sector, in- or outside its own country. They refer to everything from more sporadic information exchange or joint action to regular training or support activities. Bold lines signify that the union have representatives in and/or is a member of another organization. Bold dashed lines illustrate similar relationships between these other organizations.

Presented from the left to the right, the structure in Fig. 2.1 demonstrates that, at company level, the focal trade union may be involved in local representation and cooperation with other national unions represented in the workplace. Similar cooperation at European and global level can also exist in the form of EWCs in multinational companies having employees in at least two European countries. This may include collaborating in connection with information and consultation processes, contract negotiations with employers and even joint strikes (Banyuls et al. 2008; Müller et al. 2013). A corresponding global-level structure is still very uncommon, although there are some global corporate boards such as Global Works Councils and other similar arrangements (Steiert 2009). The bilateral level refers to direct cooperation with other unions within or outside the country and it is usually less formally organized. At sectoral level, there may be joint organizations at national level-in Sweden often in the form of union bargaining cartels. In the Nordic region, there are also sectoral Nordic trade union federations. To some extent, these mirror the European-level ETUFs, which have a coordinating role in the 43 ESSD committees. The ETUFs are normally linked to Global Sectoral Federations (GUFs), in some cases as independent subdivisions of the latter. Finally, at cross-industry level, there are both national, Nordic, European and global confederations. It can be mentioned that the three national peak-level confederations in Sweden are members of the Council of Nordic Trade Unions, the ETUC and its global counterpart International Trade Union Confederation (ITUC).

The focus of this study is primarily the collaboration at European level in and between the organizations that are in bold in Fig. 2.1. However, from time to time relationships outside of this structure enter as important in the analysis, which is why they are presented in this overview. 
We now first examine union views on cooperation within their European meta-organizations (the ETUC and the ETUFs) and then turn to the communication and coordination networks built upon direct bi- and multilateral contacts between national trade unions.

\section{Cooperation within Meta-organizations}

Meta-organizations are said to have particular difficulties, because they have other organizations as members (Ahrne and Brunsson 2008; Gumbrell-McCormick and Hyman 2013: 158-161). One of the main tensions and balance acts is that between meta-organizational authority and members' autonomy-in relation to the question of shared identity. In the case of the ETUC, it appears that these issues have been persistent. Nordic and Western European member organizations emphasize autonomy to a greater extent and show doubts to give the ETUC a strong mandate than do Southern and Central/Western European trade unions. This is based on the national traditions of the former, but also on their greater Euroscepticism and reluctance to develop supranational wage policies and regulations (Busemeyer et al., 2008; Dølvik 1997: 162-171, 243-289, 308-309, 392-394; Glassner and Vandaele 2012). Another tension is that between adhering to the 'logic of influence' and leaning towards the 'logic of membership'. It is a matter of the strategic readiness to adjust to the institutional set-up of the EU to become influential as opposed to the attraction to rely on bottom-up democracy and legitimacy, that is, what members perceive as important (Hyman 2005; Erne 2008).

When asked about these issues in survey 1, around $80 \%$ of the organizations agreed (to some or a high degree) with the need for the ETUC both to increase efforts to mobilize and pursue the interests of its member organizations and to adapt its methods to the actual decision-making in the EU (Larsson 2014). In other words, this can be interpreted as an appreciation of both the bottom-up logic of membership and the topdown logic of influence. As disclosed in a national-level study, Swedish trade union members had lower expectations on European union cooperation to improve the situation for workers than did the organizations' 
top-level representatives (Furåker and Bengtsson 2013). Whereas very few of the latter saw any reasons to engage less in issues at European level, $40-50 \%$ of their members believed it would be a good idea to do so and instead increase direct efforts to improve working conditions nationally. The tension between a logic of influence and a logic of membership thereby does not merely relate to how the ETUC should function, but also to whether unions should put a lot of effort into such transnational work at all.

As regards meta-organizational authority versus member organizations' autonomy, our survey confirmed continuity in the above variations between different regions/industrial relations regimes in Europe. We pushed the issues to their edge by asking respondents to react to the statement 'To increase their power and influence, the ETUC member organizations must be prepared to transfer authority to the ETUC'. The results in Table 2.1 reveal that besides the ETUFs, trade unions in Central/Eastern Europe more than others believed in such a strategy to enhance influence, whereas the unions in Western European countries and the Nordic region were the ones most strongly underlining autonomy for members' unions. The first column of figures is a summary indicator, showing in what direction unions in each regime/region lean. It is simply the sum of the numbers in columns $A$ and $B$ minus the corresponding sum for columns $\mathrm{C}$ and $\mathrm{D}$.

The ETUC is only one meta-organization at European level, and there has been much effort put into the cooperation through the sectoral ETUFs and the ESSDs since around the turn of the millennium. Therefore, in survey 2, we asked representatives for unions at sectoral level about the importance of collaboration through meta-organizations (from national confederations to global confederations). Table 2.2 presents the outcomes on whether it had become more or less important for the responding union in the past ten years to cooperate through different types of organizations. The balance score indicates the extent to which the importance of a specific meta-organization has increased or decreased.

There was a general tendency that trade union meta-organizations, federations and confederations at both national and supranational level were perceived to have become more important for union cooperation 


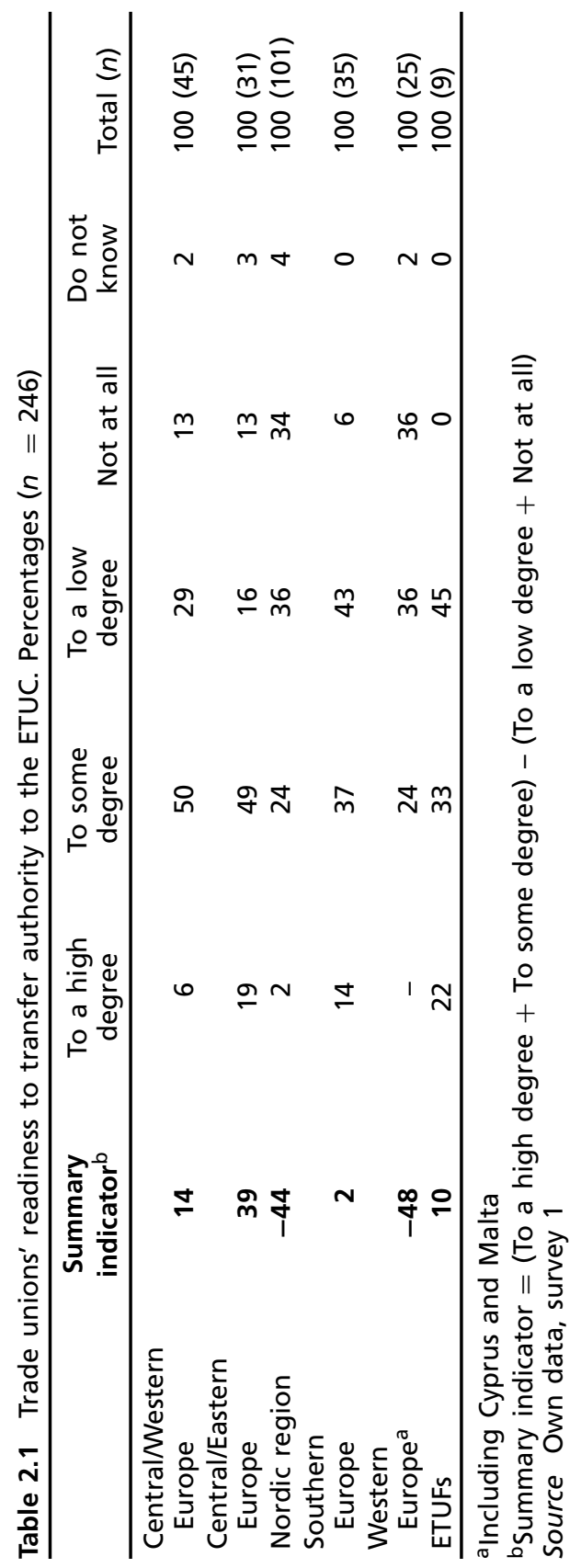




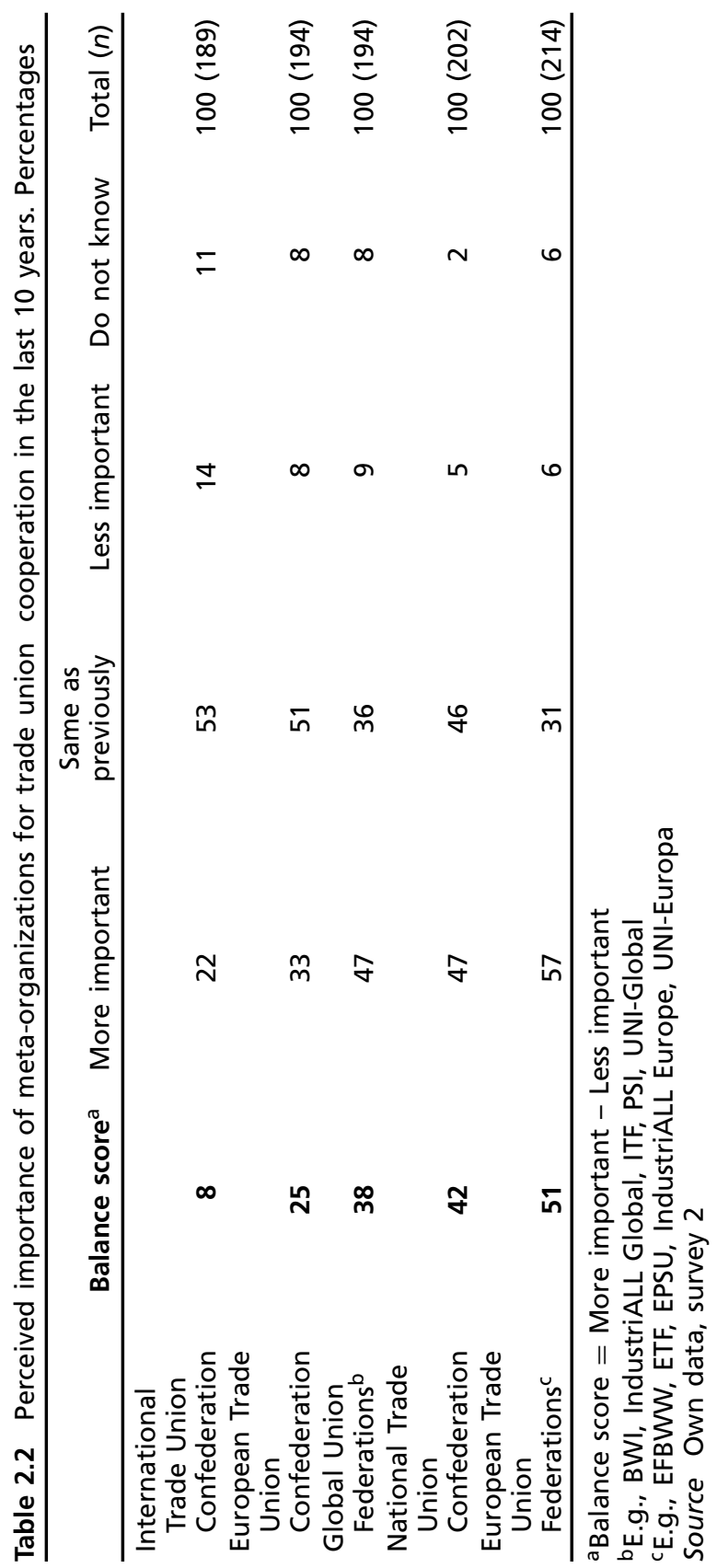


during the ten years before 2015-2016. Only a few stated that there had been a decrease in the significance of any of the meta-organizations mentioned and, with the exception for the ITUC, the balance scores are strongly positive. The ETUFs show the largest increase during this 10year period. Over half (57\%) of the unions declared that the ETUFs had become more important, which is a higher proportion than the increase in importance of their own national trade union confederation (47\%), the GUFs (47\%), the ETUC (33\%) and the ITUC (22\%).

Even though all listed meta-organizations seem to have become more important over time, sectoral-level cooperation turned out to have increased the most. In addition to the figures in Table 2.2, 74\% of the responding unions affirmed that for the future their organization would prefer to have more transnational cooperation in their own sector rather than more cooperation with unions in other sectors in their own country.

These results should be interpreted with some caution, though, since they are based on responses from unions below the peak level only, and since non-respondents may include disproportionately large numbers of unions with little interest in European cooperation. Nevertheless, it is difficult to overlook that data are in line with the institutional development at European level discussed in Chapter 1-that the sectoral level has been attributed greater importance by the European Commission since 1998, when a reform was carried out to strengthen and advance negotiations between unions and employers within the framework of ESSD committees (Rhodes 2015; cf. Degryse 2015; Prosser 2016).

To understand better in what ways the ETUFs have increased in importance, it is necessary to distinguish some of their main functions. Schematically, union cooperation through the meta-organizations of both the ETUC and the ETUFs can be said to have three main purposes: (1) to coordinate national strategies through exchanges of information, arrangements of training, and coordination of trade union action; (2) to influence EU policies and legislation through lobbying and consultation in various committees and organs; and (3) to deliver common statements and agreements through social dialogues and negotiations with European employer organizations, both at cross-sectoral and industry level. Coordination, lobbying and negotiations actually exist simultaneously within the social dialogues. 
In survey 2, we listed a number of statements on the ESSD and asked respondents to indicate to what extent they agreed. Since it requires quite some resources to take part in such joint work at European level, we included a couple of items on whether respondents thought that such collaboration really benefited the interests of their members and workers in general and whether they hesitated to participate because of the costs in time and resources (Table 2.3).

As shown in Table 2.3, there was strong recognition from the surveyed trade unions that the ESSD is important, not only to negotiate with employer organizations, but also to influence the European Commission and, especially, to strengthen transnational union cooperation. It was also commonly seen as crucial to meet the interests of members nationally. On all of these statements, not far from $80 \%$ up to nearly $90 \%$ of the responding unions agreed to some or a high degree and hence we find high summary indicators. As noted in Chapter 1, most of the outcomes of the ESSDs are non-binding declarations, joint statements, procedural documents or soft guidelines. Against that background, it might perhaps be surprising that about $77 \%$ of the unions agreed to some or a high degree in that the ESSD has a crucial role to meet the interests of workers and more than 50\% did the same regarding whether it had had great significance for the employment and working conditions of their members. On the latter statement, however, the proportion being hesitant was substantial. There was even more scepticism regarding whether the dialogues actually deliver in relation to the efforts put in. $37 \%$ of the respondents leaned towards doubting whether it was in fact worth the effort, given the time and resources required to take part in meetings, committees and working groups related to the ESSD. Still, the summary indicator is negative (note that the statement goes in the opposite direction compared to the others in the table).

The last thing to consider as concerns the transnational metaorganizations in Europe is that there exists an additional level based on supranational organizations in some regions. These are very varied, and the strongest institutionalized form of cooperation-that is, joint formal and staffed meta-organizations at both sectoral and cross-sectoral levels - is present as far as we know only in the Nordic countries. ${ }^{1}$ Moreover, the Nordic confederations have relations with the Baltic States, 


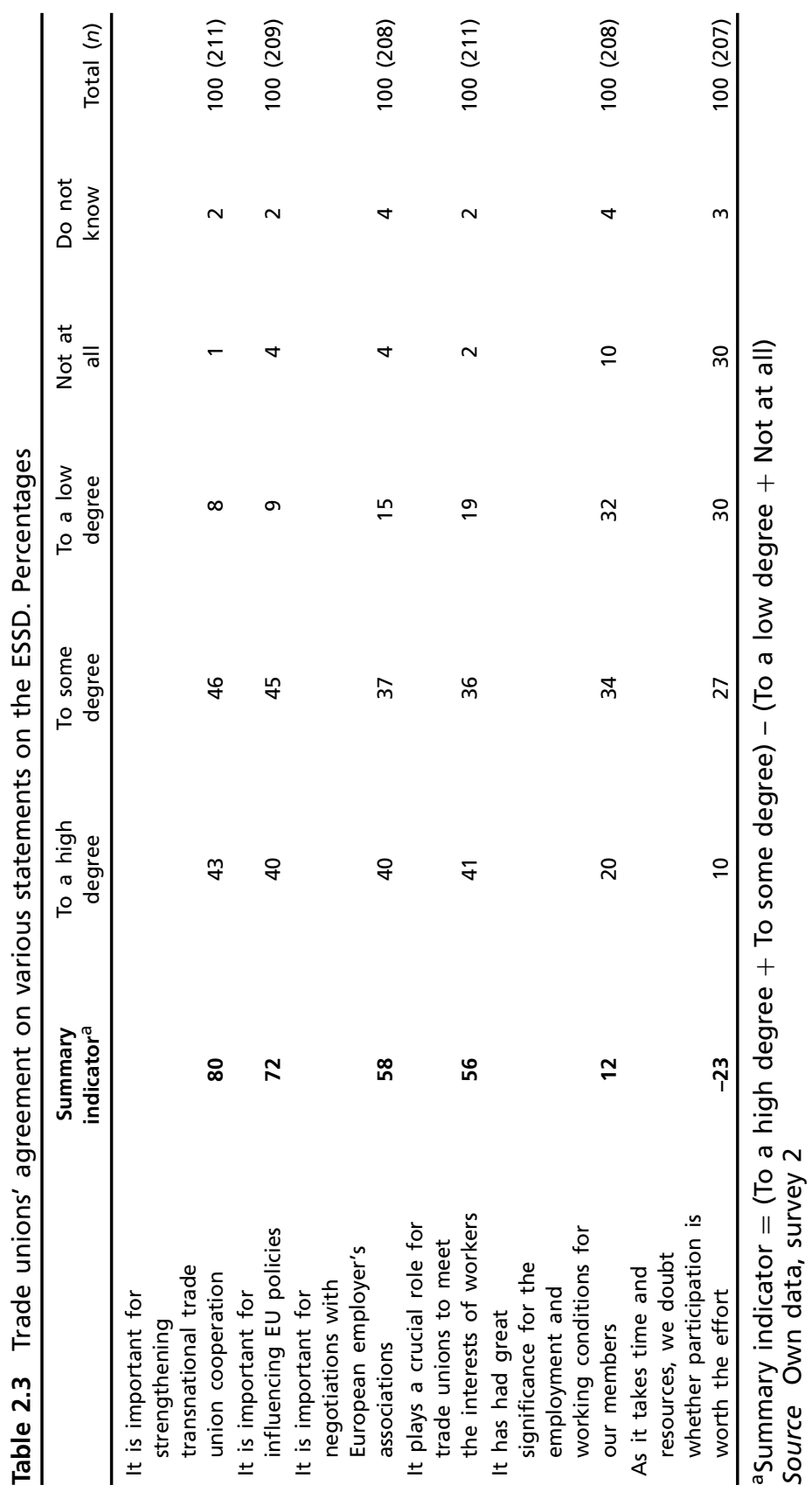


whose federations may exchange observers at meetings. There is also cooperation through the Baltic Organizing Academy and the Baltic Sea Trade Union Network. The cooperation is rather unilateral, consisting of targeted support given from Nordic to Baltic unions. These asymmetric relationships have a long tradition, but we find a certain resignation among the Nordic respondents concerning the changes in the Baltics. The development was said to be very slow and to yield quite meagre results in terms of member recruitment and organizational capacities. Overall, the differences in the Nordic unions' bilateral relations with 'core' countries in Central/Western and Western Europe and with the Baltic States respectively show the importance of organizational strength among cooperating partners. With weak partners, the relationship becomes asymmetrical and unidirectional in the flow of information and resources and thereby less useful compared to collaboration with stronger unions in Central/Western and Western Europe.

\section{Networks of Bi- and Multilateral Cooperation}

Besides the meta-organizations in Europe, there are also less formalized and institutionalized cooperation structures. These often take the form of direct bi- or multilateral communication and coordination networks between national unions. From the theoretical assumptions, the existence of formal Nordic meta-organizations may be seen as both being based on and further facilitating informal collaboration in the region. A particular feature of the Nordic cooperation seems to be its high internal synchronization compared to other areas in Europe. Through their relatively strong cultural community and similarities in traditions, Nordic trade unions have built a strong foundation of trust, which allows them a rapid response from each other when wanted, for example to obtain information or to provide support through solidarity action.

The strong Nordic coordination makes unions well-prepared for meetings in the ETUC and the ETUFs, in which they often speak with one voice (Seeliger 2019: 111-112, 169-170). When working as a coalition through the Council of Nordic Trade Unions, in relation to the ETUC they were-at least some years ago- the third largest formally organized 
and staffed coalition of national unions after the British Trade Union Confederation and the German DGB Confederation (Degryse and Tilly 2013: 73). The Nordic meta-organizations also facilitate direct, bilateral cooperation from below and have a brokerage function in collaboration with other important European trade unions. From our interviews, it seems that this mediation is most developed in the metal sector; a quote from a union representative from Sweden gives a picture of this:

[Our Nordic Sector Federation] has a formal arrangement with the Germans, in that our chairmen ... meet the leaders of the German federations... We have meetings... at... international secretary level, with the British [and] with the French. Not so much [with] the Spanish yet, and not so much [with] Italians, but on and off ... [with Eastern Europe] it is also a bit more ad hoc, and happens especially in connection with meetings [in] IndustriAll Europe.

In many regions in Europe, there are of course loose bilateral and multilateral communication and coordination networks, through which unions exchange information for use at national level. To some extent, these networks are connected to the ETUFs, in the form of organized sub-groupings based on geographical proximity. This is not always the case, though, and hence such regional networks have varying levels of organization and strength. An Italian representative of a union in the construction sector offered the following depiction:

Europe is more or less divided in areas: We have the Nordic part; the Nordic federation in the EFBWW... Then we have a predominant area, in the centre of Europe-I mean Germany, Austria, and Switzerland... and, some years ago, maybe nine, ten years, we established a sort of coordination group within the Southern Europe area. It is composed of Italy, Spain, Portugal and Belgium-who wants to be with us. We meet regularly five, six times per year and, yeah, we have a sort of coordination.

To this listing of more or less organized networks, a Czech unionist added the extended Visegrad group, including unions from Germany, Poland, Slovakia, Hungary, Austria and the Czech Republic and with interest from Swiss unions to take part: 'All representatives from this group meet 
once a year at least, and we inform each other about trade union activities in these countries and discuss different topics within our sectors'. Compared to the more organized metal sector, the international network structures in the other sectors studied seem to have been built very much from below, albeit in relation to the ETUF structures. An Italian representative of a union in the hospital sector gave an example of this, talking about an informal alliance in Southern Europe:

We have a... Mediterranean group. This is a self-organized network by the trade unions in Portugal, Spain, Italy, Greece, and France. Not part of the group but part of its work [are] Cyprus, Malta, and Israel... I say it is self-organized because the meetings are paid for by the trade unions... We work together in terms of web-networking or meeting once a year. We exchange all the information that we need on all the sectors [within EPSU].

This regional clustering of networks has been confirmed in our quantitative and social network analyses (Larsson and Törnberg 2019; Vulkan and Larsson 2019). In survey 2, respondents were asked about the 35 most important regular cooperation partners. The analyses disclosed that such networks tended to be concentrated in their own sector. The reason is a combination of from-below interest coordination and fromabove organization, founded on shared sectoral interests (Bechter et al. 2012). In addition, the ESSDs and the ETUFs function as both multicooperation arenas for making contacts and building trust for direct inter-organizational networking.

From comparisons based on the regime typology in Chapter 1, we identified a significant tendency that bilateral union cooperation was focused on partners within the same geographical region. This confirms the patterns revealed both in qualitative research of trade union networking (Gollbach and Schulten 2000; Magnusson and Murhem 2009; Marginson and Sisson 2004: 112-113) and in Nordin's (2009) quantitative studies of the metal sector. The explanation is of course that countries within the same region are neighbours, with geographical proximity and sometimes common borders. Also institutional similarities and differences, as discussed in Chapter 1, play a role. It is obvious that industrial 
relations institutions (Visser et al. 2009), economic and political contexts and challenges (Gumbrell-McCormick and Hyman 2013), trade union resources (Lehndorff et al. 2017) and cultural aspects such as language, traditions, and ideology (Hyman 2001) vary with regions in Europe.

As regards regional variation, a recurrent feature in the sectors studied-metal, transport, construction, healthcare and banking and finance-is that the Central/Western European unions tended to cluster in the core of networks, whereas unions from the other regions usually gathered more peripherally_as offshoots from the central core. We could also conclude that German unions occupied the central position in all sectors, not only in cross-border bargaining networks in the metal sector as has been shown previously but in transnational cooperation more generally (Nordin 2009; Traxler et al. 2008: 222; cf. Seeliger 2019: 172174). German unions were the main brokers between the more peripheral clusters, even though there were also some secondary brokers from other large countries in Europe.

When examining network ties, we found some differences and similarities between the regimes/regions in their balance of intra- versus interregional networking. The results of the analysis of whether a union (source) mentioned another union (target) as cooperation partner are presented in Table 2.4. As can be seen, the Nordic unions were quite intra-regionally focused, with a strong majority of their cooperation relations going to other Nordic unions. The Southern European labour organizations also had quite a strong tendency towards such an intra-regional concentration, whereas in Central/Western and Central/Eastern Europe there was a more equal balance in the selection of partners, with a greater share of cooperation links stretching out to other regions.

Looking at these results from a historical development perspective, we discover both path dependency and change. The intra-regional focus among the Nordic unions relates to their history of strong internal cooperation and possibly to their history of being somewhat reluctant Europeans as well (Seeliger 2019: 211, 226; cf. Larsson 2014, 2015). The Central/Eastern and Southern European clusters have developed more slowly and later. In the former case this was linked to the EU's enlargement to the East; the trade unions there are more fragmented and have a tendency to be more dependent on unions outside their 


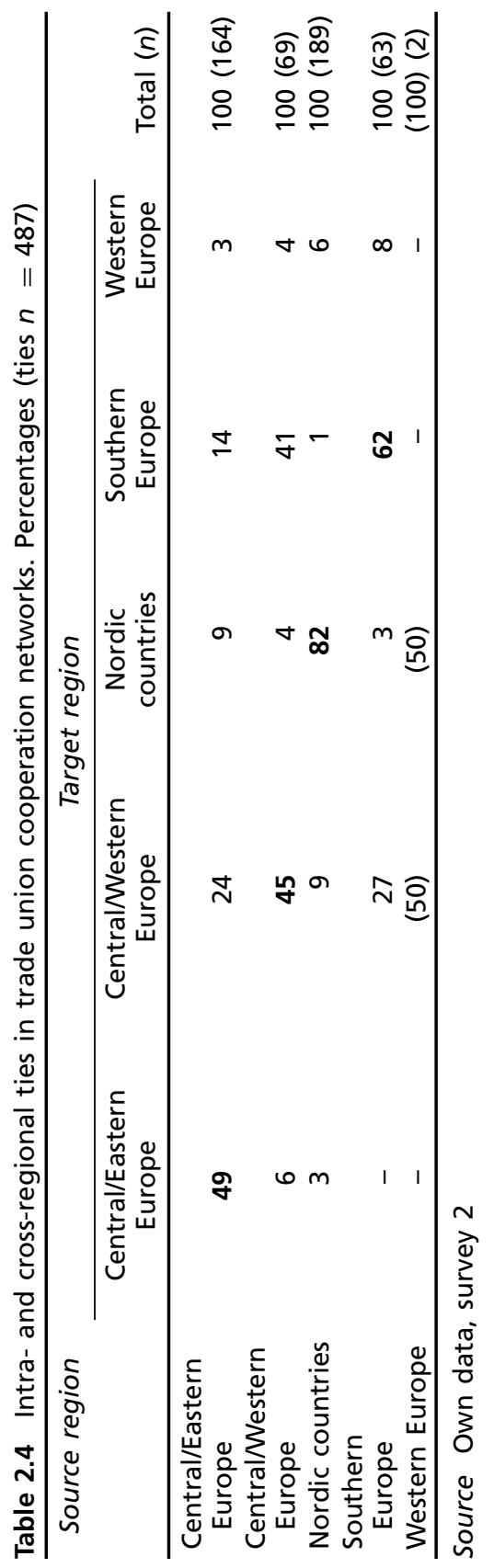


own region (Léonard et al. 2012; Seeliger 2019: 211-212). The Central/Western European labour organizations early developed cooperative networks in border regions. They cluster in the core of the sector networks and they are number one concerning links to other regional clusters. The explanation is partly their resources and influential position in Europe. Another factor is that cooperation networks tend to concentrate around border regions and Central/Western European countries, taken together, border all other regions in Europe (Gollbach and Schulten 2000; Traxler et al. 2008).

Our social network analysis confirms previous research indicating that cooperation density is especially high within the metal sector (Glassner and Pusch 2013; Magnusson and Murhem 2009). The construction sector is highly integrated as well, whereas transport and healthcare have lower levels of direct transnational networking. The results found in the latter sectors have to do with the greater fragmentation in terms of occupational or sub-sectoral unions, leading to more isolated cliques in the network.

\section{Forms of Cooperation}

The presentation above is very much focused on trade unions' general views on cooperation and the multilevel structures through which cooperation is pursued. We now turn to the more concrete forms of collaboration that unions have been engaged in - from producing joint statements to concerting common actions such as demonstrations or strikes across countries.

Through the ETUC and the ETUFs and the social dialogues coordinated via these meta-organizations, unions produce a great number of resolutions, positions, petitions, open letters, etc. Some are joint statements with employer organizations on employment relations and political and economic developments in Europe. The ETUC and the ETUFs also coordinate exchange of information, for example on collective bargaining and union actions across countries. In the period before our surveys were conducted, the ETUC organized European demonstrations, both in specific cities and coordinated across different cities (Degryse 
and Tilly 2013). In 2012, the organization even mobilized simultaneous strikes in four countries-Italy, Greece, Portugal and Spain-as a protest against the austerity measures following the economic and financial crisis in Europe. This was however something of an exception, because strikes are generally dealt with as national matters. As for the ETUFs, we can observe quite similar palettes of activities, varying between sectors. At the level further below, we find a great variety of bi- and multilateral actions, for example exchange of information or observers in collective bargaining, cooperation around training programmes, negotiations about plant restructuring, participation in demonstrations and sympathy strikes.

To get an overview of trade unions' involvement in joint activities, we questioned respondents in both surveys about these things (Furåker and Bengtsson 2013). The results in survey 1 showed that most of the labour organizations (92\%) exchanged information on collective agreements, either on a regular or a more sporadic basis. Over two-thirds (71\%) of them collaborated on training programmes for union officials. More than half of the unions (52\%) engaged in coordinating negotiations on plant restructuring and closures - regarding issues such as redundancies, wages and training - and more than a third (38\%) exchanged observers or negotiators in collective bargaining.

Transnational action can be coordinated either through the European meta-organizations - the ETUC and the ETUFs - or in the cooperation structures existing globally above these, or regionally below them. Table 2.5 shows the responding unions' participation in actions of transnational kind as organized by the ETUC, the ETUFs and other bodies during the last three years. It also tells us something about the balance between softer and more contentious forms of action. The majority $(80 \%)$ had participated in writing statements, petitions and open letters. Slightly over half $(56 \%)$ of them had been involved in demonstrations and boycotts across borders and almost a fifth of the organizations stated that they had taken part in more contentious forms of action such as overtime bans, strikes or blockades with cross-border reach.

Since the greatest variation emerged in the demonstration and boycotts category, we carried out a more detailed analysis of it, showing quite large regional and sector differences (Larsson 2014). The main results 


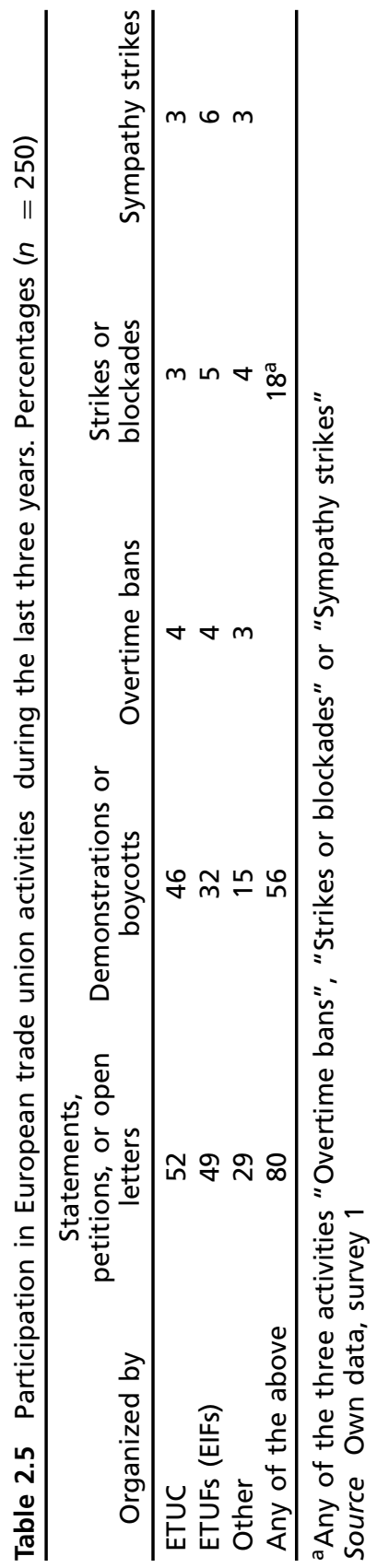


were that the Central/Western and Southern European unions had much higher degrees of participation in transnational demonstrations and boycotts than unions from the other regions, and the Nordic organizations had the lowest level of participation. Cross-sectoral peak-level confederations turned out to have more cooperation than all sectoral trade unions, with the exception of transport that obviously had organized several activities across borders during the three-year period before the survey was conducted in 2011-2012. When examining the role of sizewhich was used as a proxy for resources-large organizations quite unsurprisingly showed more participation in cross-border demonstrations and boycotts than smaller ones.

We also performed a similar analysis of the trade unions' views on the importance to engage more in cross-national demonstrations, boycotts, overtime bans and strikes in the future (Larsson 2014). This revealed that peak-level confederations were particularly inclined to have more of these things in the future, as were unions from Central/Western and Southern Europe compared to unions from Central/Eastern Europe and the Nordic countries. This suggests that differences in national-level industrial relations traditions affect the way cross-national activities are approached.

In order to get a deeper understanding of these activities at sectoral level, we had a similar question in survey 2, while extending the period to five years and also examining the extent to which such cooperation had taken place at national level. The purpose was to explore the balance between national and international cooperation. The results are shown in Table 2.6 and for comparative reasons we add a column with the corresponding results from survey 1 in which peak-level confederations were included.

Some main points can be drawn attention to from these results. Sectoral unions had had a great deal of cooperation with other unions in their own countries, but we also find high figures for cooperation with unions abroad in the same sector. Both more contentious forms of action such as boycotts and strikes and coordination of collective bargaining remained highly nation-based activities. Softer activities-like exchange of information on collective bargaining, authoring joint statements, petitions or open letters and organizing training-were more transnational. 


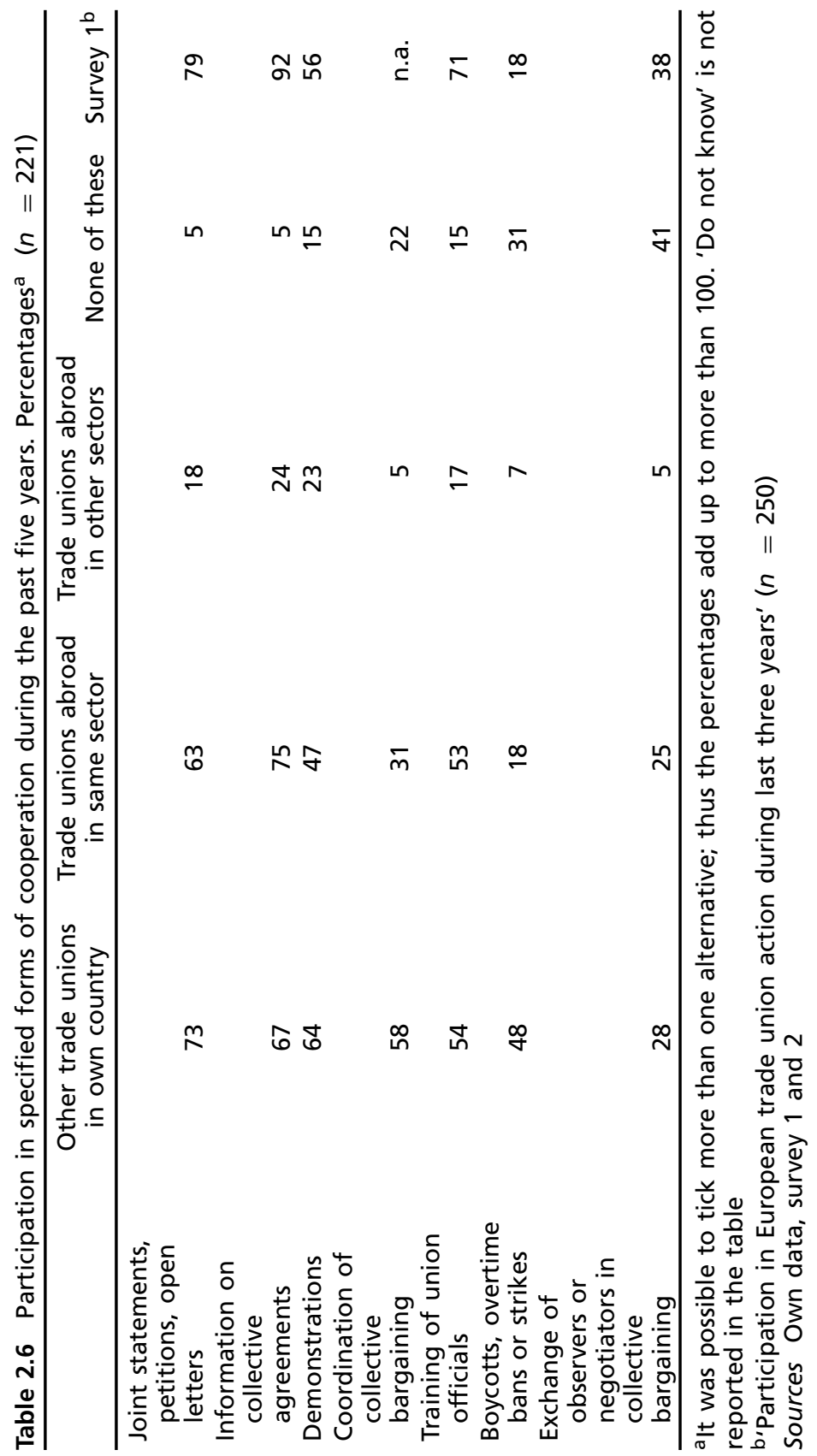


In addition, the second survey suggests that sectoral trade unions had somewhat lower degrees of cooperation than peak-level confederations, which can be seen in that the numbers in the second column of figures are mostly lower than those from survey 1 in the last column. It is also worth noting that, if ranked, the levels of transnational cooperation in the two forms mentioned are consistent across the two surveys.

As there was quite great variation in the extent to which unions cooperated transnationally, we created an index of all the relevant forms to measure the overall level of cooperation. This aimed at studying whether regime and sector differences and the resources of a union (i.e., size) could explain the patterns (Vulkan and Larsson 2019). The regression results (not shown) indicated that the size of organizations was strongly significant: the larger the union, the more of transnational cooperation. We did not find any markedly strong differences across industrial relations regimes/regions, but some significant sectoral dissimilarity became visible. Labour organizations in the services industry were, on average, less engaged in various forms of cooperation than those in other sectors. Unions in the metal sector were involved in most forms of cooperation, and unions in transport and construction as well as trans-sectoral unions had an intermediate position.

\section{Channels for Influencing EU Policies}

One important reason for trade unions to cooperate transnationally in Europe is their interest in influencing the development of EU policies and regulations. In Chapter 1, we identified the different access points in this respect through social dialogues, consultations in various committees and fora and joint lobbying. Besides these channels there are national routes as well to influence the EU. Unions may, for example, lobby their own national members of the European parliament and they may try to have some bearing on their own government's position in the Council or other fora to impact on policy development (Clauwaert 2011; Greenwood 2007: 127-130; cf. Larsson 2015).

When, in survey 1, asked about whom their trade union cooperated with to influence EU policies, it turned out that the national route was 
very important for unions. $75 \%$ of the responding unions stated that they collaborated to some or to a high degree with national authorities and political parties to achieve this kind of influence (Table 2.7). In contrast, the least important route was other NGOs or networks, with only $34 \%$ of the labour organizations indicating that they cooperated with these to the same degree. The ETUFs, the trade unions' own Brussels offices, the ETUC, various cross-national regional networks and members of political groups in the European parliament were on average ranked in between.

To understand the variation in how trade unions cooperate to affect EU policies and what channels they use to do that, we elaborated the analysis somewhat further. We created an index of the overall usage of different channels, by adding the seven items in Table 2.7, and run regressions with industrial relations regimes/regions, sectors and size of the organization as independent variables to explain differences (Larsson 2015). The results confirmed that there was more cooperation to influence the EU among larger unions than among smaller ones. Additionally, collaboration was somewhat less in services than in manufacturing, transport and construction and it was highest among the peak confederations. In terms of regimes or regions, the Central/Western European unions had the highest levels of overall cooperation. The Western and Central/Eastern European labour organizations had the lowest levels, while the Nordic and the Southern European unions appeared in a middle position.

Furthermore, we examined the balance between what we categorized as 'own channels' and 'cooperative channels' to affect EU policies. The former is defined as trade unions' cooperation through their own national government, political parties or the national Brussels offices and the latter category means cooperation within the ETUC and the ETUFs. As shown in Fig. 2.2, we placed the zero point (intercept) in the balance score at 0.3 , which was the mean of the total. This indicates a slight overall tendency that unions collaborated more through their own channels (positive numbers in balance score) than through the cooperative channels (negative numbers).

Central/Western European unions can be said to make up sort of a benchmark for the others: they not only had the highest degree of cooperation to influence EU policies, but also deviated the least from the 


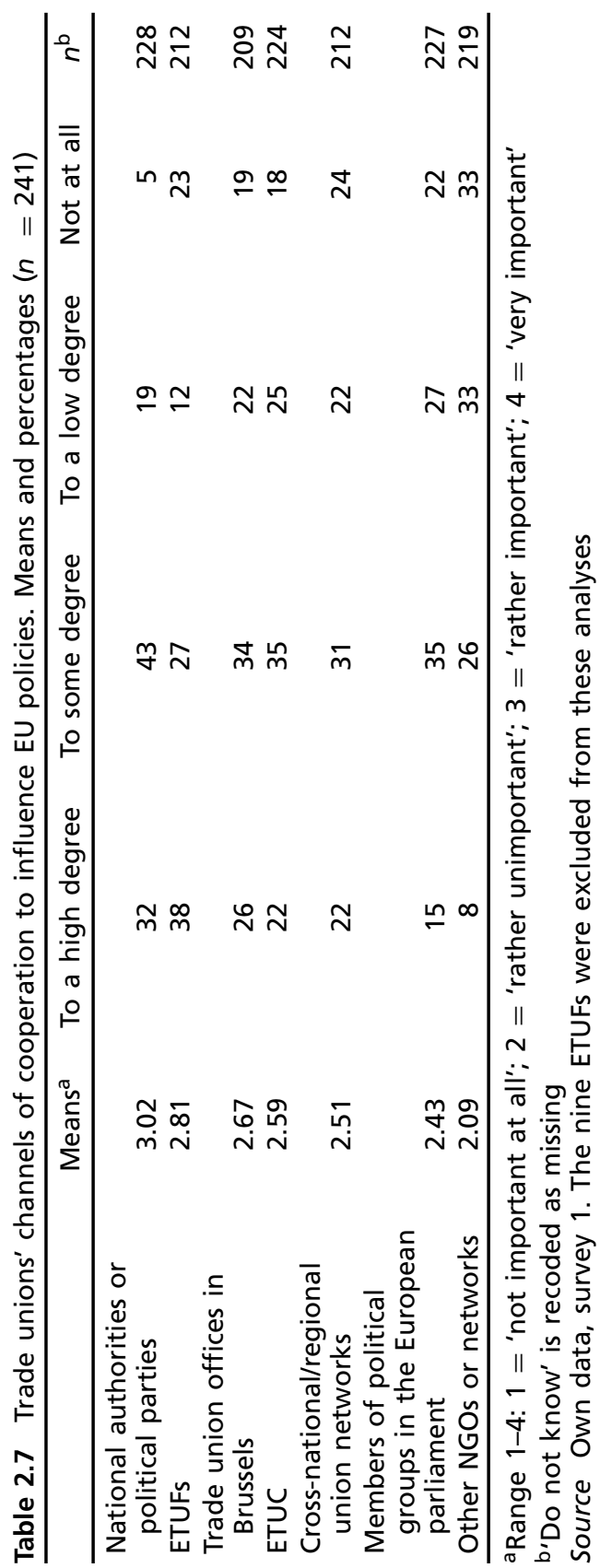




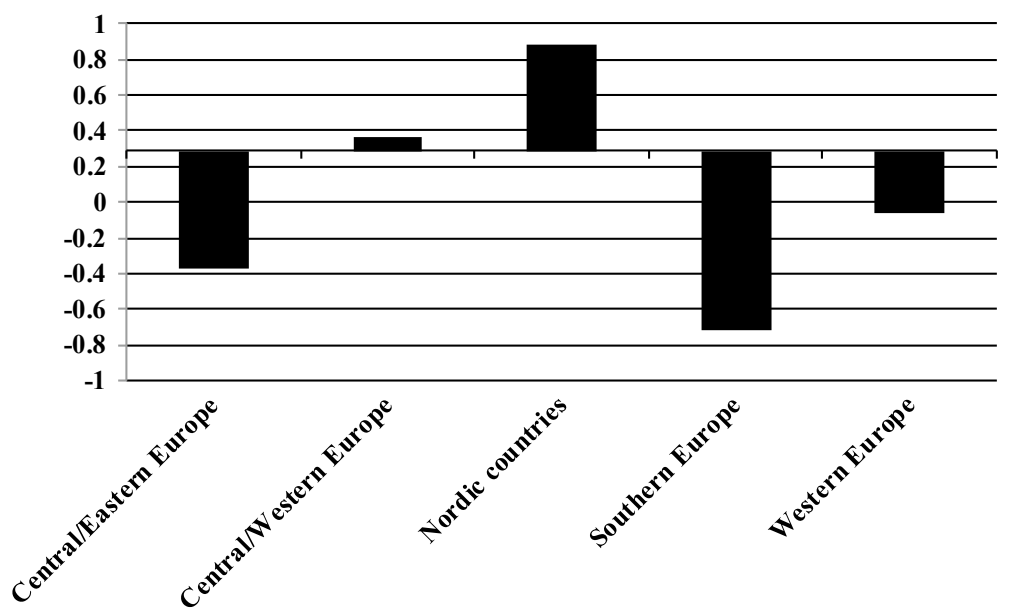

Fig. 2.2 Balance scores ${ }^{a}$ on own channels vs. cooperative channels, by region $(n=209-228)$

a Balance scores range from 1 to -1 . They are based on the means on the first four items in Table 2.7 (National authorities or political parties + Trade union offices in Brussels) - (ETUFs + ETUC). 'Do not know' is recoded as missing Source Own data, survey 1

overall balance between collaboration through their own channels and the cooperative channels through the ETUC and the ETUFs. In comparison, we see that the Nordic unions tended to orient themselves more to the first alternative than to the second, whereas the Southern (in particular) and the Central Eastern European unions had the contrary tendency to emphasize cooperation through the meta-organizations.

\section{Focus and Topics of Cooperation}

The analyses above make clear that some of the differences in the forms and intensity of cooperation are related to differences in industrial relations regimes/regions, sectors and organizational resources. However, trade unions also face quite varying challenges because of specific political and economic developments at both national and sectoral/industry level (Gumbrell-McCormick and Hyman 2013: 37-46). Thus, they cannot be expected to be interested or engaged in cooperation around the 
same general issues or topics. We bring up a couple of examples of this in the case studies following in Chapters 3 and 4, but already in the current section we give a brief overview of what topics and issues that unions in different sectors and countries considered important to collaborate on nationally and transnationally.

In survey 2, we questioned the union representatives about both their existing cooperation on a number of different issues and how important they found them to be for the future. Before going into the details, we can note that the overall results in Table 2.8 verify some of the findings presented above. There was a higher prevalence of national compared with transnational collaboration and most of the latter was focused on trade unions in the same sector. The outcomes also confirm that most unions were engaged in some cooperation, either national or transnational (Vulkan and Larsson 2019).

By looking at the differences between the levels of existing cooperation with other unions in their own country and cooperation with foreign unions in the same sector, we discover some broad tendencies in Table 2.8. Wages were not surprisingly a very nationally based issue. The topics of unemployment/employment, working time, and employment protection legislation had a similar tendency to be nationally oriented, but to a lesser extent. In contrast, migration and recruitment of members tended to be similarly strong in transnational cooperation. At the same time, these are topics on which approximately $30-40 \%$ of the responding unions indicated no cooperation at all.

Regarding how important the topics were believed to be for future transnational cooperation (column on the far right), the results indicate that topics on which unions already cooperated were seen as the most important. Still, there are some exceptions to this. When comparing how high the different issues were ranked (in percentages and means), we find that the category of professional matters seems to be given less weight for the future compared to existing levels of cooperation. Similarly and more significantly, two of the absolute core issues for trade unions, wages and working hours, were perceived as more important for future cooperation in comparison with existing cooperation on these topics. This may be a reaction to the consequences of the financial crisis when many labour organizations in Europe had to accept wage and working time 


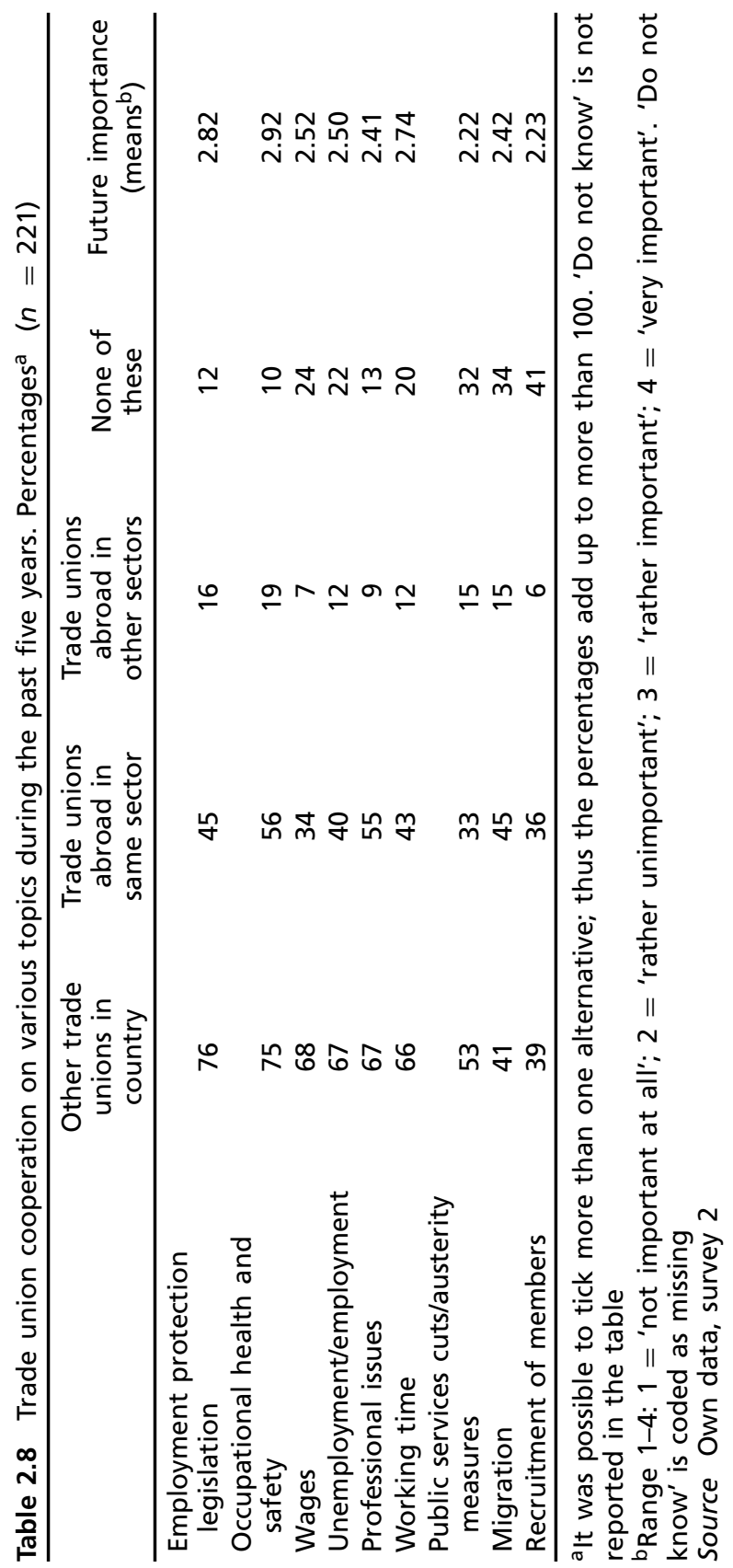


reductions. It may also signal that respondents believed that such questions-which are still nationally bound-would need to be discussed more across Europe (Dribbusch et al. 2017; Müller and Platzer 2017). One critical part of the European-level cooperation on wages has to do with the minimum wage issue, to which we will come back in Chapter 3.

We ran regressions to examine the effects of industrial relations regimes/regions, sectors and the size of organizations on all these items (Vulkan and Larsson 2019). Previous outcomes were substantiated, indicating that size played a clear role for the level of transnational cooperation and that unions in the services sector normally cooperated less than unions in the other sectors. When it comes to the selection of specific topics to work on, sectoral differences turned out to have a greater part than industrial relation regimes/regions. This is not very unexpected, because the challenges that trade unions and their members meet vary with sectoral and industry-specific conditions. Labour organizations in construction showed an especially strong tendency to focus on occupational health and safety and migration issues. Unions organizing public sector employees, particularly in healthcare, cooperated more than others on the topic of public services cuts/austerity measures. Likewise, unions in the metal sector directed more attention than others to cooperation around unemployment/employment.

\section{Obstacles to Cooperation}

Given the views regarding the importance and benefits of transnational cooperation and the extent of existing collaboration through networks and meta-organizations, one might wonder whether unions believe that everything is good enough already. The answer must in spite of this be 'no', insofar as many of them stated that more cross-border activities would be desirable. Therefore we want to take a closer look at what factors that hinder and facilitate cooperation.

To begin with obstacles, we asked unions to rate to what degree different factors hindered union cooperation in Europe. The response patterns appear in Table 2.9. The items are ranked by the total means and the first 


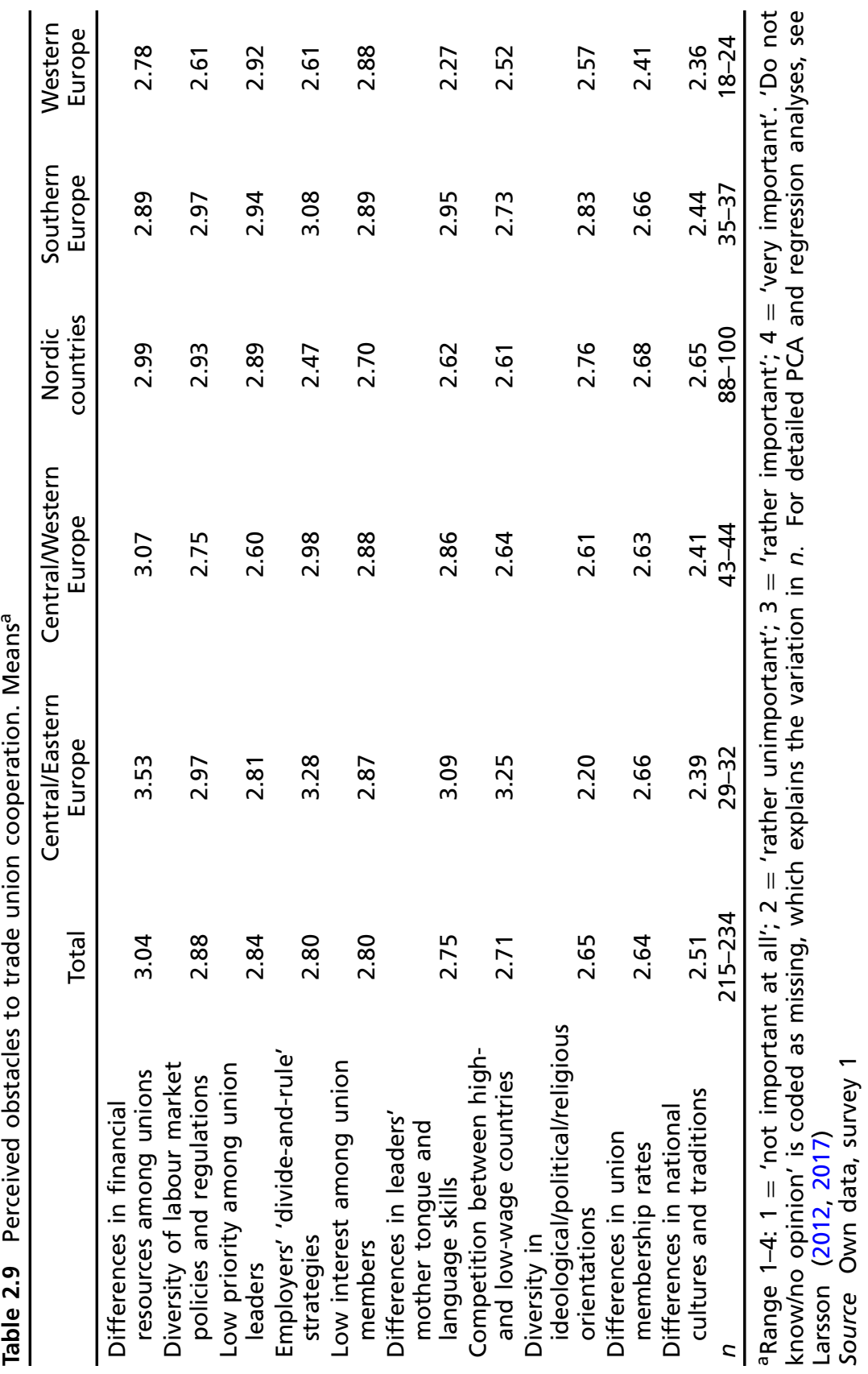


column of figures shows that differences in financial resources were generally regarded as the greatest obstacle of the ten factors listed, while differences in national cultures and traditions were considered least important. Yet, even the last in ranking gets a total mean of 2.51 on a scale ranging from 1 to 4 . In other words, cultural factors were not regarded as unimportant, only less so than other factors. A general conclusion from Table 2.9 could be that cross-border trade union cooperation has many difficulties to defeat to develop positively.

From the compared means analysis in the following columns-and originally tested in regressions (Larsson 2017) —we find marked variations in how some of these obstacles were weighed by trade unions in different industrial relations regimes/regions. Central/Eastern European organizations underscored difficulties with financial resources, competition between high- and low-wage countries, and employer organizations' power strategies. Also Southern European unions seemed to deem the latter to be a problem, but this result was not statistically significant in the regressions. Nordic unions attributed employers' power strategies to be clearly less important. We also discovered some significant differences in the means on the three items related to culture. Compared to other organizations, particularly those from the Central/Eastern Europe, Western European unions regarded language issues to be less of an obstacle. Difficulties based on ideological, political or religious diversity were highlighted by Southern European respondents, while being viewed as slightly less problematic by Central/Eastern European unions. Finally, the Nordic unions rated differences in national cultures and traditions somewhat higher as a barrier than did unions from the other regions. Once again, the largest sectoral difference was that between, on the one hand, labour organizations in manufacturing and construction emphasizing resources and, on the other hand, those representing services and professional groups stressing members' low prioritization and interest as an obstacle to cross-border cooperation (Larsson 2012).

The interviews largely confirmed that differences in financial resources - and especially the lack of resources among small unions and unions in Central/Eastern Europe-were a great problem for cooperation. It is also a dilemma for those with more resources, when their 
poorer partners cannot take part. The difficulty of prioritizing working at European level —in light of the lacking interest among members-was touched upon in the interviews too. It connects to the balance between the logic of influence and the logic of membership. Differences in labour market policy and regulations have varying implications in different sectors. Whereas in healthcare it was frequently a matter of diverse financing systems and educational requirements across Europe, in manufacturing the discussion was about competition related to wage differentials and more or less explicit strategies of governments to support certain industries. At a more general level, divergences in the regulations of working conditions and the wage-setting processes make it difficult to reach an understanding of what to aim for with cooperation in the ETUC and the ETUFs - an issue to which we come back in the analysis of the minimum wage issue in Chapter 3. Cultural factors were talked about quite extensively in the interviews, which is why we return to them immediately after paying attention to some of the facilitators for trade union cooperation.

\section{Factors Facilitating Cooperation}

If the above are some of the most important obstacles to transnational union cooperation, are there corresponding facilitators and, if so, which are they? It may seem likely that these comprise ways to overcome the existing barriers related to resources, institutional differences, low priorities, resistance to European-level social dialogue from employers, etc. For the purpose of validating the question on obstacles, we inquired about the importance of a number of factors for union cooperation in Europe to become successful (Table 2.10).

The results presented in Table 2.10 back up some of the outcomes regarding the obstacles to cooperation. From the means we can draw the conclusion that cultural factors had less weight than similarities in labour market policies and regulation, similarities in occupational interests and well-developed personal networks and relations between trade union leaders. The three culture-related items were, more or less, ranked in the same way as they were as obstacles: language was considered more 


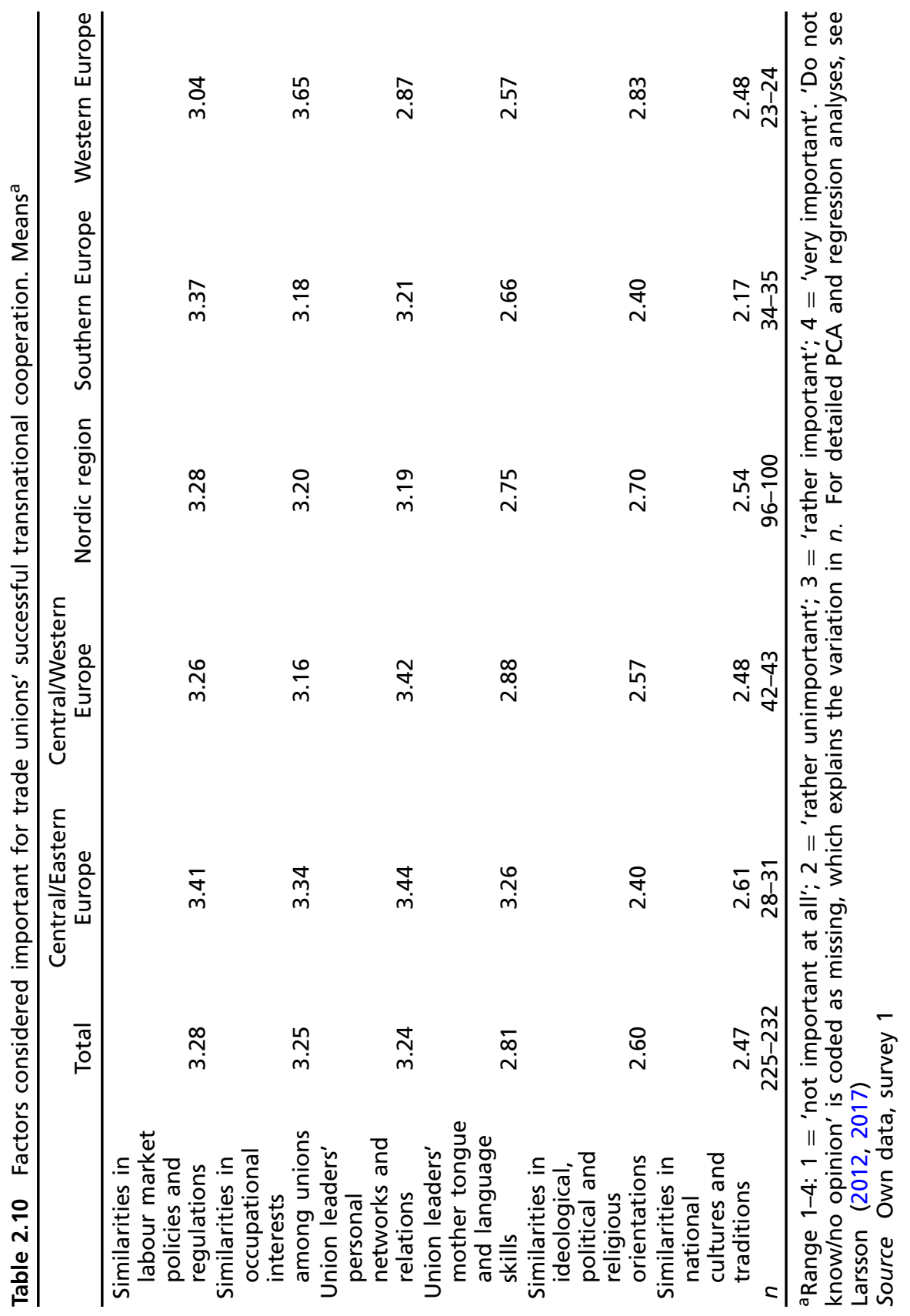


important than similarities in ideological, political or religious orientations and similarities in national cultures and traditions came last among the six factors listed.

Just as on the impediments to cooperation, we find some significant differences in means when comparing industrial relations regimes/regions (Larsson 2017). Central/Eastern and Western European unions scored higher on the importance of similarities of occupational interests between unions. Further, Western European respondents put markedly less weight on the role of personal networks than did respondents from the other regimes. If these two results are somewhat puzzling, the outcomes on cultural factors are noticeably more in line with the previous analysis of how obstacles were perceived. Central/Eastern European unions, which had the highest score on language as a barrier to cooperation, also emphasized the significance of language skills for successful cooperation. The Nordic labour organizations highlighted the value of similar ideological, political and religious orientations-as did those from Western Europe. Finally, the Southern European trade unions were relatively less inclined to stress similarities in national culture and traditions for successful transnational union cooperation.

\section{Cultural Obstacles to Cooperation}

We now turn to the interview study to specify the cultural obstacles to transnational trade union cooperation in Europe-what problems exist, how and why cultural differences create problems and what cultural borders the respondents identified within Europe. The analysis is linked to the previous quantitative investigation in that the three surveyed cultural factors will be treated in the order of importance, as uncovered by results above. First, we look at how and why language differences create problems. Then the focus is on obstacles related to unions' ideological, political or religious orientations. Finally, we bring up what the interviews tell us about the role of differences and borders between national cultures.

The interviews verified that differences in mother tongue and lack of foreign language skills were considered great obstacles (Larsson 2017, 2020). Especially Central/Eastern European respondents saw language 
barriers as 'strong', 'essential', 'huge' or even as 'the major obstacle' (cf. Henning 2015a). Some interviewees from the English- and Germanspeaking countries found these barriers to be less of a problem, since good translations and interpretations exist. Others, however, acknowledged the language difficulties, as for instance in this quotation from a British unionist:

We're very lucky because [we're] English... In fact, some of our ETUF meetings are only conducted in English, so that can be a barrier for other organizations... Some people come and they never say anything. And then other organizations, they can only send someone who is quite good at speaking English.

The ETUC and ETUF congresses normally admit funding for up to six language interpretations. At committee meetings, there are fewer interpretations, while seminars and working groups are typically held in English only, forcing participants to speak 'some kind of joint bad English'. This is problematic since some participants do not have the skills and others are unwilling even to try to speak the meeting language. Those lacking English skills thus have to forgo or bring their own interpreters (cf. Henning 2015a). Interpretation is not uncomplicated either, because the precision or even the very substance may get lost in translation. Terms and concepts are embedded in, and always refer to, a cognitive (and often normative) content and a common world of reference (Barbier 2013: 109; cf. Hyman 2004). As a consequence, there are difficulties of the kind mentioned as expressed by an Italian union representative (Larsson 2020: 7):

The Nordic countries [have] a different understanding of what 'austerity' means; what 'crisis' in the public sector means... You need to build a common vocabulary ... to understand what the others are saying. And if the words are different-like 'privatisation' or 'public sector' or what the meaning is of 'autonomous', 'independent'... This is the major obstacle.

Translations of central documents may create problems too, because there can be misunderstandings due to differences in connotations of concepts. These linguistic problems are not only costly and hamper 
understanding, but they also reduce the possibility for some unions to influence the discussion. These organizations are forced to choose between having representatives staying silent or sending representatives on the basis of their language skills rather than their expertise. An illustration of this is taken from a Latvian interviewee (Larsson 2020: 7):

If we have two or three people who are capable of speaking in English, the same people have to be competent in various themes and specific subjects, and it is very hard to do that at a good level... It is very hard to come out with an argument or a competent opinion of things.

The absence of a common language tends to make overall trust building harder as well since small talk becomes more difficult. Some union representatives asserted that it is in small talk that joint ideas are developed and that 'the real business gets done in the meeting beforehand or over lunch'.

Trade unions also differ in their ideological, political and religious orientations and it is well known that such differences can create problems for collaboration. As discussed in Chapter 1, some are more of 'business unions' mainly representing their members' interests as cartels, while others are more political or 'movement unions' trying to represent the interests of the working class or workers in general (Gumbrell-McCormick and Hyman 2013: 6-28; Henning 2015b; Hyman 2001). Moreover, there are organizations adhering to radical leftist political ideas, reformist and consensus-oriented unions and those that are more on the conservative side. The deepest rift in ideology appearing in the interviews was said to go between consensus- and conflict-oriented traditions. These are not neatly grouped regionally, but a main North-South divergence was mentioned recurrently (cf. Henning 2015a; Larsson 2014). We can give an example of how it was communicated by a Spanish representative (Larsson 2020: 11):

There is a clear division North-South. We mobilize the workers at the social and political level; we have general strikes, mass demonstrations 
in the streets. The Nordic unions have collective bargaining at the sectoral level or national level... It is, therefore, not easy to establish one [common] way of trade union action at the European level.

Both other Southern European and Nordic union officials confirmed this divide between cooperating and compromising with employers versus having more conflictual and confrontational relations (cf. Lovén Seldén 2014). To some extent, the latter attitude may create misunderstandings and even disapproval. Some Nordic interviewees talked about unions in Southern Europe as being more of 'campaign organizations', which do not take their seat at the negotiating table, but instead 'go in the streets and shout'. Whereas they saw themselves as 'more constructive', they thought others would find them a bit 'wimpish', 'not passionate enough', or 'woody'. This was further supported when some Southern European representatives characterized the Nordics as 'less European' or as not being solidary.

Besides the North-South division, respondents also made comments on an East-West difference (cf. Henning 2015b). Some Central/Eastern European unions were said to have very different views, shaped by their post-communist legacy of having strong connections to political parties. Still, several interviewees acknowledged that North-South and EastWest typologies were too schematic, because there are different traditions even within regions and countries_-some being more homogenous and others more fragmented. The internal fragmentation of the trade union movement in some countries can, though, be taken as another aspect of cultural difficulties, implying that unions from more homogenous contexts find it difficult to cooperate with those that are not even on speaking terms within their own country (cf. Henning 2015a, b).

The factor that was attributed least importance in the survey was differences in national cultures and traditions. It is perhaps a more abstract dimension than the one on ideological, political and religious variations. There are certainly overlaps between the two dimensions, but the one of national cultures and traditions is presumably more general in character. When we-in our interviews - discussed the North-South split in Europe, we once again ran into some schematic divisions, exemplified by an Italian union representative (Larsson 2020: 8): 
It is easier for us [Italians] to have cooperation with the Mediterranean countries-I am talking about Spanish and French ...because we have more or less the same culture, and it is easier for us to have good relations... When we talk with our colleagues from Scandinavia, it is complicated [for them] to understand our problems, because, you know, they are very far from us.

In a similar vein, a British respondent viewed relations with French colleagues as difficult, using the following words: '/T/hat is partly about language, but it is also about the traditions and the way they do things'. This cultural divide is linked to the ideological gap discussed above, but it was seen as going beyond ideology (Larsson 2020: 10):

The Nordic countries are used to negotiating, the Germans are, and we [British] are... It is culture! And it is easier for us to do business with the Nordics and the Germans, because they understand, or we have a common interest in doing a deal. Whereas it seems to me-and I am aware that I am stereotyping culturally-the French and the Spanish and the Greeks in particular come to those meetings to make a point, to make a speech.

These differences appear not only in basic values and conceptions, but also in traditional everyday practices like what is expected in social situations and how one expresses oneself. They include everything from how delegates from various countries stick to the starting times of meetings to how much they talk and how they interact socially. Such things may seem trivial, but they affect the internal processes in the European organizations. One example is the difference between the more 'talkative' Southern European delegates and the more 'taciturn' Nordic, as shown in a study of speech patterns at ETUC Executive Committee meetings (Furåker and Lovén Seldén 2016). At such meetings, the Nordic delegates are coordinated through their joint organizations (Seeliger 2019: 169-170, 212-213, 226). Their position is already negotiated and they have little need to mark a unique position, as explained by a Swedish unionist: 'So we give a few statements to explain our position, and then the others get to talk'. This was said to lead to confusion and even irritation from others, who, in contrast 'must express their organization and 
its ideas, values and agenda', irrespective of others voicing a similar line of argument.

Cultural features are important for how the member organizations of the ETUC and the ETUFs perceive both the content and legitimacy of decisions. A representative of a joint Nordic organization suggested that the decision-making in these organizations 'does not have the same strong formalistic approach to democracy that we have here'. There is seldom any voting except in congresses and the process is rather consensusseeking, followed by an attempt to spell out the decisions in an understandable summary —as argued by a Swedish unionist (Larsson 2020: $10)$ :

We have our model in Sweden-how to do it. The Germanic model: then you have the question 'Who is for; who is against; someone who abstains?' We don't do it like that here. This must be learned. If you don't, you immediately will kick up a row. And why? Because then they will not understand what they have decided... So, clearly, cultural differences make it difficult. And that is why it is necessary to understand these cultural differences... I have seen those who have failed with that. The consequence was crazy decisions - if any decisions at all.

Cultural differences can hence have quite serious consequences. They affect not only whether decisions are perceived as legitimate, but also how their content is understood — and may as a result also influence how well they are implemented.

Some cultural borders between East and West were mentioned and they were from time to time associated with the question of ideology. It was said that some Central/Eastern European societies were 'hierocracies' and 'post-communist' rather than 'democratic' (cf. Henning 2015b). This was recognized by both Western and Central/Eastern European respondents. There could, however, also be resistance to such categorization: A trade union official from Latvia emphasized that the Baltic States are not part of a Central/Eastern European culture, but have more 
in common with the Nordic countries. A Hungarian representative dismissed the idea of a great cultural divide, arguing that the cultural divergences in Europe were nothing compared to those between Europe and other continents:

Today in Europe, this is no problem; more and more people work in England, Germany, Sweden. More Hungarian people work in Sweden. I think there is no distance in culture. No problem. Other nations: Asian nations, Muslim, or African nations have other cultures, but Hungary, no problem. Hungary is very, very similar to Germany. We have a lot of German companies.

This kind of relativity of cultural borders also appeared when the interviews centred on regions that are presented as culturally homogeneous. For many, the Nordic countries make up such a region, because they 'live in the same cultural world' and 'see things the same way'. Nevertheless, when viewed more closely, these similarities were sometimes dissolved. In practice, there could be cultural heterogeneity in the joint Nordic organizations (Larsson 2020: 9):

The Danish... are very straightforward... If you are quiet, you have nothing to say, from a Danish perspective. While in Finland, it may well be that you are talking in a different way, you have a bit longer pauses and so, but if you sit in a meeting you are expected to be asked by the chairman of the meeting about what to do. And if you are not asked, you leave the meeting feeling trampled on.

It is important not to exaggerate these cultural variations and the difficulties they create for trade union cooperation. As we could see in Table 2.9, cultural differences were not perceived as the most important obstacles to cooperation. It is possible for actors to overcome many of the cultural barriers. An Italian representative stated this plainly: 'It is not easy at the very beginning. But if you participate in many meetings, during many years, you can do it'. What is more, we should not neglect the existence of solidarity across countries and the shared values in the European political culture and trade union movement (Gajewska 2009; Pernicka and 
Glassner 2014). If there were nothing of this kind, union cooperation would not be possible at all.

\section{Note}

1. At cross-sectoral level, there is the Council of Nordic Trade Unions; at sectoral level in the five sectors studied, there are the Industrial Employees in the Nordic region, the Nordic Building and Woodworkers' Federation, the Nordic Transport Workers' Federation, Nordic Financial Unions and the Nordic Public Employees Trade Unions.

\section{References}

Ahrne, G., and N. Brunsson. 2008. Meta-organizations. Cheltenham: Edward Elgar.

Banyuls, J., T. Haipeter, and L. Neumann. 2008. European Works Council at General Motors Europe: Bargaining Efficiency in Regime Competition? Industrial Relations Journal 39 (6): 532-547.

Barbier, J.C. 2013. The Road to Social Europe: A Contemporary Approach to Political Cultures and Diversity in Europe. London: Routledge.

Bechter, B., B. Brandl, and G. Meardi. 2012. Sectors or Countries? Typologies and Levels of Analysis in Comparative Industrial Relations. European Journal of Industrial Relations 18 (3): 185-202.

Bengtsson, M., and P. Vulkan. 2018. After the Great Recession: Unions' Views on Transnational Interest and Cooperation. Nordic Journal of Working Life Studies 8 (3): 111-133.

Busemeyer, M.R., C. Kellerman, A. Petring, and A. Stuchlik. 2008. Overstreching Solidarity? Trade Unions' National Perspectives on the European Economic and Social Model. Transfer: European Review of Labour and Research 14 (3): 435-452.

Clauwaert, S. 2011. 2011: 20 Years of European Interprofessional Social Dialogue: Achievements and Prospects. Transfer: European Review of Labour and Research 17 (2): 169-179.

Degryse, C. 2015. The European Sectoral Social Dialogue: An Uneven Record of Achievement? Brussels: ETUI. 
Degryse, C., and P. Tilly. 2013. 1973-2013: 40 Years of History of the European Trade Union Confederation. Brussels: ETUI.

Dølvik, J.E. 1997. Redrawing Boundaries of Solidarity? ETUC, Social Dialogue and the Europeanization of Trade Unions in the 1990s. Oslo: Fafo.

Dribbusch, H., S. Lehndorff, and T. Schulten. 2017. Two Worlds of Unionism? German Manufacturing and Service Unions Since the Great Recession. In Rough Waters: European Trade Unions in a Time of Crises, ed. S. Lehndorff, H. Dribbusch, and T. Schulten, 97-220. Brussels: ETUI.

Erne, R. 2008. European Unions: Labor's Quest for a Transnational Democracy. Ithaca: Cornell University Press.

ETUC. 2019. ETUC Action Program 2019-2023. Brussels: ETUC.

Furåker, B., and M. Bengtsson. 2013. On the Road to Transnational Cooperation? Results from a Survey among European Trade Unions. European Journal of Industrial Relations 19 (2): 161-177.

Furåker, B., and K. Lovén Seldén. 2016. Patterns of Speech Activity at ETUC Executive Committee Meetings, 2005-2012. European Journal of Industrial Relations 22 (1): 57-71.

Gajewska, K. 2009. Transnational Labour Solidarity: Mechanisms of Commitment to Cooperation Within the European Trade Union Movement. London: Routledge.

Glassner, V., and K. Vandaele. 2012. Which Way Towards Europeanization of Trade Union Strategies? Regional Differences in Trade Union Officers' views. Paper Presented at ILERA World Congress 2012, Philadephia.

Glassner, V., and T. Pusch. 2013. Towards a Europeanization of Wage Bargaining? Evidence from the Metal Sector. European Journal of Industrial Relations 19 (2): 145-160.

Gollbach, J., and T. Schulten. 2000. Cross-Border Collective Bargaining Networks in Europe. European Journal of Industrial Relations 6 (2): 161-179.

Greenwood, J. 2007. Interest Representation in the European Union, 2nd ed. Basingstoke: Palgrave Macmillan.

Gumbrell-McCormick, R., and R. Hyman. 2013. Trade Unions in Western Europe: Hard Times, Hard Choices. Oxford: Oxford University Press.

Henning, K. 2015a. Not Dominant but Existent: Involvement of Trade Unions from EU Member States of Eastern Enlargement in European Trade Union Federations. In Interest Representation and Europeanization of Trade Unions from EU Member States of the Eastern Enlargement, ed. C. Landgraf and H. Pleines, 73-111. Stuttgart: Ibidem.

Henning, K. 2015b. Trade Unions and Industrial Relations in the EU Member States of Eastern Enlargement. In Interest Representation and Europeanization 
of Trade Unions from EU Member States of the Eastern Enlargement, ed. C. Landgraf and H. Pleines, 53-71. Stuttgart: Ibidem.

Hyman, R. 2001. Understanding European Trade Unionism: Between Market, Class and Society. London: Sage.

Hyman, R. 2004. Is Industrial Relations Theory Always Ethnocentric? In Theoretical Perspectives on Work and the Employment Relationship, ed. B.E. Kaufman, 265-292. Champaign, IL: Industrial Relations Research Association.

Hyman, R. 2005. Trade Unions and the Politics of the European Social Model. Economic and Industrial Democracy 26 (9): 9-40.

Keune, M., and P. Marginson. 2013. Transnational Industrial Relations as Multi-level Governance: Interdependencies in European Social Dialogue. British Journal of Industrial Relations 51 (3): 473-497.

Larsson, B. 2012. Obstacles to Transnational Trade Union Cooperation in Europe-Results from a European Survey. Industrial Relations Journal 43 (2): 152-170.

Larsson, B. 2014. Transnational Trade Union Action in Europe-The Significance of National and Sectoral Industrial Relations. European Societies 16 (3): 378-400.

Larsson, B. 2015. Trade Union Channels for Influencing European Union Policies. Nordic Journal of Working Life Studies 5 (3): 101-121.

Larsson, B. 2017. Cultural Borders as Obstacles to European Trade Union Cooperation. In Cultural Borders and European Integration, ed. M. Andrén, 53-67. CERGU: Gothenburg.

Larsson, B. 2020. Cultural Obstacles to Trade Union Cooperation in Europe. Nordic Journal of Working Life Studies 10 (1): 1-16.

Larsson, B., and A. Törnberg. 2019. Sectoral Networks of Transnational Trade Union Cooperation in Europe. Economic and Industrial Democracy. Published online ahead of print. https://doi.org/10.1177/0143831x19853871.

Lehndorff, S., H. Dribbusch, and T. Schulten. 2017. European Trade Unions in a Time of Crises-An Overview. In Rough Waters: European Trade Unions in a Time of Crises, ed. S. Lehndorff, H. Dribbusch, and T. Schulten, 7-35. Brussels: ETUI.

Léonard, E., E. Perin, and P. Pochet. 2012. The European Sectoral Social Dialogue as a Tool for Coordination Across Europe? In The European Union and Industrial Relations: New Procedures, New Context, ed. S. Smismans, 56-77. Manchester: Manchester University Press. 
Lovén Seldén, K. 2014. Laval and Trade Union Cooperation: Views on the Mobilizing Potential of the Case. International Journal of Comparative Labour Law and Industrial Relations 30 (1): 87-104.

Magnusson, L., and S. Murhem. 2009. European Integration and Nordic Trade Unions. In Regional Cooperation and the International Organizations: The Nordic Model in Transnational Alignment, ed. N. Götz and H. Haggrén, 185-200. Oxon: Routledge.

Marginson, P., and K. Sisson. 2004. European Integration and Industrial Relations: Multi-level Governance in the Making. Basingstoke: Palgrave Macmillan.

Müller, T., and H.-W. Platzer. 2017. The European Trade Union Federations: Profiles and Power Resources-Changes and Challenges in Times of Crises. In Rough Waters: European Trade Unions in a Time of Crises, ed. S. Lehndorff, H. Dribbusch, and T. Schulten, 303-329. Brussels: ETUI.

Müller, T., H.-W. Platzer, and S. Rüb. 2010. Transnational Company Policy and Coordination of Collective Bargaining-New Challenges and Roles for European Industry Federations. Transfer: European Review of Labour and Research 16 (4): 509-524.

Müller, T., H.-W. Platzer, and S. Rüb. 2013. Transnational Company Agreements and the Role of European Works Councils in Negotiations. Brussels: ETUI.

Nordin, P. 2009. Membership, Dependencies and Free Riding in Networks-A Case Study of the European Metal Sector. Industrial Relations and Human Resources Journal 11 (6): 73-92.

Pernicka, S., and V. Glassner. 2014. Transnational Trade Union Strategies Towards European Wage Policy: A Neo-institutional Framework. European Journal of Industrial Relations 20 (4): 317-334.

Prosser, T. 2016. Economic Union without Social Union: The Strange Case of the European Social Dialogue. Journal of European Social Policy 26 (5): 460-472.

Rhodes, M. 2015. Employment Policy: Between Efficacy and Experimentation. In Policy Making in the European Union, ed. H. Wallace, M.A. Pollack, and A.R. Young, 294-317. Oxford: Oxford University Press.

Seeliger, M. 2019. Trade Unions in the Course of European Integration: The Social Construction of Organized Interests. London: Routledge.

Steiert, R. 2009. Multinationals and Unions. World Company Councils and World Works Councils as Strategies of Union Counter-Force. IndustriALL Global Union. http://www.industriall-union.org/sites/default/files/ migration/imf/RelatedFiles/10030911201810005/2009_RS_WKA_WBR_ Gewerkschaften_eng_endg3.pdf. 
Traxler, F., and E. Mermet. 2003. Coordination of Collective Bargaining: The Case of Europe. Transfer: European Review of Labour and Research 9 (2): 229-246.

Traxler, F., B. Brandl, V. Glassner, and A. Ludwig. 2008. Can Cross-Border Coordination Bargaining Work? European Journal of Industrial Relations 14 (2): 217-237.

Visser, J., M. Beentjes, M. van Gerven, and V. Di Stasio. 2009. The Quality of Industrial Relations and the Lisbon Strategy. Industrial Relations in Europe 2008, 45-72. Luxembourg: Publications Office of the European Union.

Vulkan, P., and B. Larsson. 2019. Patterns of Transnational Trade Union Cooperation in Europe: The Effects of Regimes, Sectors and Resources. European Journal of Industrial Relations 25 (2): 147-162.

Open Access This chapter is licensed under the terms of the Creative Commons Attribution 4.0 International License (http://creativecommons.org/ licenses/by/4.0/), which permits use, sharing, adaptation, distribution and reproduction in any medium or format, as long as you give appropriate credit to the original author(s) and the source, provide a link to the Creative Commons license and indicate if changes were made.

The images or other third party material in this chapter are included in the chapter's Creative Commons license, unless indicated otherwise in a credit line to the material. If material is not included in the chapter's Creative Commons license and your intended use is not permitted by statutory regulation or exceeds the permitted use, you will need to obtain permission directly from the copyright holder. 